\title{
Use of Fungicides and Biological Controls in the Suppression of Fusarium Crown and Root Rot of Asparagus Under Greenhouse and Growth Chamber Conditions
}

\author{
T. C. Reid, Graduate Research Assistant, and M. K. Hausbeck, Associate Professor, Department of Plant \\ Pathology; and K. Kizilkaya, Statistical Consultant, College of Agricultural and Natural Resources Statistical \\ Consulting Service, Michigan State University, East Lansing 48824
}

\begin{abstract}
Reid, T. C., Hausbeck, M. K., and Kizilkaya, K. 2002. Use of fungicides and biological controls in the suppression of Fusarium crown and root rot of asparagus under greenhouse and growth chamber conditions. Plant Dis. 86:493-498.

Growth chamber, greenhouse, and field experiments were conducted with fungicides and biological control agents, including nonpathogenic isolates of Fusarium oxysporum, to test their ability to control disease caused by $F$. oxysporum $\mathrm{f}$. sp. asparagi and $F$. proliferatum. In greenhouse studies with asparagus seedlings in soil, Trichoderma harzianum strain T-22, benomyl, and fludioxonil treatments increased root weight and decreased root disease compared with the infested control when a low level of $F$. oxysporum f. sp. asparagi and F. proliferatum was used. The fungicide fludioxonil limited plant death caused by Fusarium spp. at high inoculum levels, whereas T. harzianum strain T-22 was not effective. Nonpathogenic isolates of $F$. oxysporum were effective in limiting Fusarium disease on asparagus seedlings in culture tubes, although isolates differed in their ability to control disease caused by $F$. oxysporum f. sp. asparagi and $F$. proliferatum. In greenhouse studies, no significant differences in plant death were found between asparagus plants growing in media infested with $F$. oxysporum f. sp. asparagi and $F$. proliferatum and left untreated, and those treated with nonpathogenic F. oxysporum. The efficacy of fungicides and biological control products to control Fusarium crown and root rot under commercial field conditions could not be evaluated due to low disease pressure.
\end{abstract}

Fusarium proliferatum (T. Matsushima) Nirenberg and Fusarium oxysporum Schlechtend.:Fr. f. sp. asparagi S. I. Cohen are the primary pathogens causing Fusarium crown and root rot of asparagus, which is an economically important disease in Michigan and throughout the world $(3,10,11,14,15,17,31)$. Efforts to manage the disease through the development of resistant cultivars have met with limited success $(12,29)$. Although the majority of the fungicides evaluated have not provided adequate disease suppression $(9,21)$, the fungicide thiabendazole was effective in New Zealand studies (14), but is not registered for use on asparagus in the United States. Currently, fungicides are not used to manage the disease in Michigan.

Asparagus is a deep-rooted perennial, making application of chemical or biological controls difficult once the crop is established. Commercial asparagus is seeded

Corresponding author: T. C. Reid

E-mail: reid@vamtech.com

This study was supported by funding from the Michigan Agricultural Experiment Station, Michigan State University Extension, the Michigan Department of Agriculture, the Michigan Farm Bureau (GREEEN cooperative), and by Michigan asparagus growers and processors.

Accepted for publication 14 December 2001.

Publication no. D-2002-0228-02R

(C) 2002 The American Phytopathological Society and grown in specialized seedling nurseries for 1 year before crowns (plants) are dug out and planted into production fields. Infection of seedlings while in the nursery predisposes a crop to severe decline $(9,21)$, making the seedling stage a critical time to apply control measures for Fusarium crown and root rot.

The potential of biological control agents to suppress disease caused by Fusarium spp. has been evaluated on a number of crops $(2,4,8,19,22-24,26)$. The fungus Trichoderma harzianum has been shown to be effective against $F$. oxysporum f. sp. asparagi on asparagus seedlings in greenhouse trials in potting media (1). Nonpathogenic strains of $F$. oxysporum also have consistently shown effectiveness against $F$. oxysporum f. sp. asparagi in growth chamber and greenhouse studies, and were shown to be effective in one field study, but not in others $(3,7,31)$.

The objective of this study was to determine whether fungicides or biological control agents, including nonpathogenic isolates of $F$. oxysporum, could control disease caused by $F$. oxysporum f. sp. asparagi and $F$. proliferatum in growth chamber, greenhouse, and field experiments.

\section{MATERIALS AND METHODS}

Greenhouse experiments with fungicides and biological control organisms. Asparagus seeds were sterilized in a mixture of $100 \mathrm{ml}$ of acetone and $2.5 \mathrm{~g}$ of benomyl (5 $\mathrm{g}$ of Benlate 50WP; DuPont Crop
Protection, Wilmington, DE) by spinning on a magnetic stir plate for $24 \mathrm{~h}$, rinsing three times each in acetone and distilled water, then spinning for $1 \mathrm{~h}$ in $1.05 \%$ sodium hypochlorite $(20 \%$ household bleach), rinsing five times with sterile distilled water, and blotting on a sterile paper towel $(6,13)$. Seeds then were germinated in the dark on sterile water agar petri plates, and planted into 96-ml plug trays filled with soilless medium (Baccto High Porosity Professional Planting Mix; Michigan Peat Co., Houston, TX) as soon as hypocotyls emerged.

Plants were grown for 14 days, then clean, uniform seedlings were transferred to $512-\mathrm{ml}$ plastic pots filled with steamsterilized sandy loam soil. Soil for treatments containing $F$. oxysporum f. sp. asparagi and $F$. proliferatum was infested by growing cultures of the pathogens on sterile millet seed for 2 weeks, drying the seed in sterile paper bags, grinding the millet, and mixing each pathogen in equal parts into steam-sterilized sandy loam soil in a cement mixer for $4 \mathrm{~h}$ (32). Separate experiments were performed with a high (200,000 CFU/g of soil) and low concentration $(12,600 \mathrm{CFU} / \mathrm{g}$ of soil) of pathogen inoculum. Infested millet seed was added to 94.6 liter of soil at $156 \mathrm{~g}$ for each pathogen for the high inoculum concentration and $15 \mathrm{~g}$ each for the low concentration. Estimation of $\mathrm{CFU} / \mathrm{g}$ of soil was determined by serially diluting soil onto selective media and counting the number of fungal colonies formed. Each experiment was conducted twice.

Treatments included an uninfested control (untreated) mixed with sterile ground millet seed, an infested control, and infested soil drenched with either benomyl at $0.6 \mathrm{~g} /$ liter, thiabendazole (Mertect 340-F; Syngenta Crop Protection, Inc., Greensboro, NC) at $2.34 \mathrm{ml} /$ liter, fludioxonil (Maxim 4FS; Syngenta Crop Protection, Inc.) at $1.56 \mathrm{ml} /$ liter, or T. harzianum strain T-22 (RootShield; BioWorks, Inc., Geneva, $\mathrm{NY}$ ) at $8.98 \mathrm{~g} / \mathrm{liter}$. Thiabendazole was excluded from the experiment with low pathogen concentrations because the manufacturer does not plan to label this product for use on asparagus (personal communication, Syngenta Crop Protection Inc.). All drenches were applied 2 days after planting.

Each treatment for both experiments consisted of 10 plants grown in individual 
pots $(512 \mathrm{ml})$ in a completely randomized design. Plants were fertilized twice weekly with Peters 20-20-20 fertilizer (Grace Sierra Horticultural Products Company, Milpitas, CA) at $200 \mathrm{ppm}$ and were grown for 5 weeks, then evaluated. Effectiveness of the treatments in the experiments with a high inoculum level was evaluated by counting the number of dead plants weekly, and effectiveness of the treatments in the experiment with a low inoculum level was evaluated by measuring the fresh weight of roots and shoots directly after they were harvested and visually estimating the percentage of the root system covered with lesions (0 to $100 \%$ ).

Greenhouse experiments were performed to test the ability of nonpathogenic F. oxysporum isolates to control Fusarium crown and root rot in a potting mixture. Seedlings of cv. Mary Washington (Rupp Seeds, Wauseon, OH) were disinfested by the method previously described and planted into 96-ml plug trays filled with soilless medium. Plants were grown for 3 weeks; then clean, uniform seedlings were transferred to 512-ml plastic pots filled with steam-sterilized sandy loam soil and soilless medium in a 5:1 ratio either infested with $F$. oxysporum f. sp. asparagi and $F$. proliferatum, infested with these pathogens and nonpathogenic isolates of $F$. oxysporum, or left uninfested. Fusarium spp. were added to the soil by mixing infested ground millet seed into the potting mixture in a cement mixer for $2 \mathrm{~h}$. Pathogens were added to the potting mixture as $F$. oxysporum f. sp. asparagi isolate $2-7$ and $F$. proliferatum isolate $\mathrm{P}-67$, both from Michigan asparagus fields at $1 \mathrm{~g} /$ liter of soil each. Nonpathogenic $F$. oxysporum isolates (D-1 and F-21) were added to pathogen-infested potting mixture at 1 $\mathrm{g} /$ liter of soil each. Eighteen plants in separate pots $(512 \mathrm{ml})$ were used for each treatment and pots were arranged in a completely randomized design. The plants were fertilized twice weekly with Peters 20-2020 fertilizer at $200 \mathrm{ppm}$ and were grown for 6 weeks before the number of dead plants in each treatment was counted. The experiment was conducted twice.

Growth chamber experiments evaluating nonpathogenic $F$. oxysporum isolates for control of Fusarium crown and root rot of asparagus. Four commercial asparagus fields in Oceana County, MI and a research field on the campus at the Michigan State University (MSU) Plant Pathology Farm were sampled for Fusarium spp. between October 1997 and April 1998. Isolates were collected from asparagus crown and root tissue (17 isolates), the vascular tissue at the base of asparagus ferns (97 isolates), and soil from asparagus fields (224 isolates). All plant tissue was rinsed in $20 \%$ household bleach for 30 to $60 \mathrm{~s}$, rinsed in sterile distilled water, and placed on Komada's media (20), which is selective for Fusarium spp. Cultures from soil were obtained by diluting onto Komada's media and incubating for 5 to 7 days at $25^{\circ} \mathrm{C}$. Fungal cultures exhibiting vigorous fluffy mycelial growth were transferred to carnation leaf agar (CLA) and allowed to grow for 10 to 14 days under fluorescent plant lights. Single-spore subcultures were made and placed on CLA. After 10 to 14 days, colonies were identified as $F$. oxysporum according to the criteria of Nelson et al. (25). Isolates ( $n=$ 227) were tested for pathogenicity in a method adapted from Stephens and Elmer (30). Spore solutions $\left(1 \times 10^{6}\right.$ spores $\left./ \mathrm{ml}\right)$ were made from CLA plates, and $0.5 \mathrm{ml}$ of spore solution from each isolate was added to each of five sterile, capped, 16-by-150$\mathrm{mm}$ test tubes containing 2-week-old asparagus seedlings grown in $6.5 \mathrm{ml}$ of Hoagland's solution agar. Asparagus seed (cv. Mary Washington) were sterilized according to the methods of Damicone and Manning (6) and germinated on water agar plates, then aseptically placed in the culture tubes once their radicals had emerged. Cultures were allowed to colonize the seedling tubes for 28 days in a growth chamber under fluorescent lights $(16 \mathrm{~h}$ of light/day) at temperatures of $25^{\circ} \mathrm{C}$ (day), and $20^{\circ} \mathrm{C}$ (night). Disease symptoms were evaluated by visually estimating the percentage of the root system exhibiting lesions or collapse. Cultures in which each of the five seedlings exhibited disease symptoms on less than $5 \%$ of their roots were considered nonpathogenic, and were put into long-term storage on silica gel according to the method described by Windels et al. (33).

Forty-one isolates of $F$. oxysporum from Michigan asparagus fields identified as nonpathogens were tested for their potential to control Fusarium crown and root rot. Two additional isolates of $F$. oxysporum from other crops (celery and cyclamen) were found to be nonpathogenic on asparagus and were included in this screen. Each of the isolates was added as $0.5 \mathrm{ml}$ of spore solution $\left(1 \times 10^{6}\right.$ spores $\left./ \mathrm{ml}\right)$ from CLA plates to eight 2-week-old 'Mary Washington' asparagus seedlings grown in Hoagland's solution agar in sterile culture tubes as previously described. Tubes were capped, and cultures were allowed to colonize the tubes for 7 days, after which 0.5 $\mathrm{ml}$ of spore solution $\left(1 \times 10^{6}\right.$ spores $\left./ \mathrm{ml}\right)$ from a virulent, pathogenic isolate of $F$. oxysporum f. sp. asparagi (2-7) isolated from a diseased asparagus crown at the MSU Plant Pathology Farm was applied to four tubes colonized by each isolate; and $0.5 \mathrm{ml}$ of a spore solution $\left(1 \times 10^{6}\right.$ spores/ml) from a virulent, pathogenic isolate of $F$. proliferatum (P-67) isolated from the base of a diseased asparagus stalk from a commercial asparagus production field in Oceana County, MI was applied to the other four tubes. Pathogens were allowed to infect the plants for 28 days, after which the seedlings were evaluated for root rot severity by a visual estimation of the percentage of the root system exhibiting lesions or collapse.

Five isolates were chosen from this test for further study based on their potential to control both $F$. oxysporum f. sp. asparagi and $F$. proliferatum. These isolates, designated D-1, S-13, E-12, F-21, and 2-5, were evaluated in a more rigorous experiment conducted in the growth chamber. Each isolate was added to 16 2-week-old seedlings in test tubes containing $0.5 \mathrm{ml}$ of solution $\left(1 \times 10^{6}\right.$ spores $\left./ \mathrm{ml}\right)$ in the manner previously described, allowed to colonize for 7 days, then challenged with the virulent isolate of $F$. oxysporum f. sp. asparagi. A control was included in the experiment by adding $0.5 \mathrm{ml}$ of sterile distilled water to one set of tubes, instead of a spore solution from a nonpathogenic isolate. Test tubes with the 16 replicates of each treatment were arranged in a completely randomized design and placed in a growth chamber with fluorescent lights on a 16-h cycle with temperatures of $25^{\circ} \mathrm{C}$ (day) and $20^{\circ} \mathrm{C}$ (night). The experiment was conducted in the same manner for F. proliferatum. Results of all experiments were evaluated by visually estimating the percentage of the root system that was discolored or collapsed. Dead plants were considered to be $100 \%$ infected.

Field experiments with fungicides and biological controls. Plots were established in Oceana County, MI in two nonadjacent commercial fields previously cropped to asparagus and having a history of Fusarium seedling blight. Asparagus seed (unknown Jersey cultivar) were sown into $1.22-\mathrm{m}$ beds in three rows spaced $45.72 \mathrm{~cm}$ apart at a rate of one seed every $3.18 \mathrm{~cm}(8.97$ $\mathrm{kg}$ seed/ha) using a Gaspardo vacuum planter (Gaspardo Co., Morsano, Italy). Treatment plots consisted of a $3.05-\mathrm{m}$ section of the center row on each bed. Five feet of buffer were left between each treatment within a row and data were taken from a 2.13-m section in the center of each plot. Treatments were arranged in a randomized complete block design with six blocks.

Treatments were all drench applications made to a 22.86-cm-wide section of the center seedling row (except where noted), applied immediately following seeding, and consisted of the following: (i) an untreated control (water only applied), (ii) the fungicide fludioxonil at a high rate (Maxim 4FS at 42.06 liter/ha), (iii) fludioxonil at a low rate (Medallion at $2.03 \mathrm{~kg} / \mathrm{ha}$; Syngenta Crop Protection Inc.), (iv) fludioxonil at a high rate (Maxim 4FS at 42.06 liter/ha) applied every 30 days until harvest, (v) fludioxonil at a low rate (Medallion at $2.03 \mathrm{~kg} / \mathrm{ha}$ ) applied every 30 days until harvest, (vi) the biological control fungus T. harzianum strain T-22 (24.64 $\mathrm{kg} / \mathrm{ha}$ ), (vii) the fungicide benomyl (1.17 $\mathrm{kg} / \mathrm{ha}$ ), (viii) nonpathogenic isolates of the fungus $F$. oxysporum (infested, ground 
pearl millet seed at $429.25 \mathrm{~kg} / \mathrm{ha}$ ) broadcast over the treatment row and worked into the soil $20 \mathrm{~cm}$ deep before planting, (ix) uninfested ground pearl millet seed $(429.25 \mathrm{~kg} / \mathrm{ha})$ broadcast over the treatment row and worked into the soil before planting, and (x) fludioxonil (at $0.11 \mathrm{ml} / \mathrm{kg}$ of Maxim 4FS) applied as a seed treatment.

At the end of the season (7 September, field 1; 15 September, field 2), plants were dug, roots and shoots weighed, plant height measured, the number of shoots per plant counted, and the root system visually evaluated for the total root area (percent) exhibiting lesions.

Statistical analysis. All analyses were conducted using the Mixed Model procedures of SAS statistical analysis software (SAS Institute Inc., Cary, NC), except for those involving the number of dead plants, which were analyzed using the Exact procedure of LogXact statistical analysis software (Cytel Software Corporation, Cambridge, MA). Before the analyses were carried out, data on the percentage of root system exhibiting lesions (growth chamber and greenhouse experiments) and fresh weight of shoots (greenhouse experiments) were transformed using the arcsine square root and $\log$ transformations, respectively (28). Differences between treatments were determined by using least squared means comparisons with Bonferroni adjustment factor $(P<0.05)$. Data from the two replications of each experiment are presented together unless significant experiment by treatment interactions were found.

\section{RESULTS}

Greenhouse experiments with fungicides and biological control organisms. A high level of pathogen inoculum resulted in plant death in all treatments except for the uninfested control (Fig. 1). By week five, all plants were dead in both the infested control and $T$. harzianum strain $\mathrm{T}-22$ treatments, significantly more than in any other treatment. An average of 6.5 (65\%) plants were dead after 5 weeks with the benomyl treatment, significantly more than either the fludioxonil treatment or the uninfested control. An average of two plants $(20 \%)$ died over the 5 weeks in the fludioxonil treatment, which was comparable to uninfested control and thiabendazole treatments.

When the lower pathogen inoculum level was used, all plants survived, regardless of treatment. Fresh shoot weights for the uninfested control varied between the two low inoculum experiments, resulting in a significant experiment by treatment interaction. In the first experiment, the only significant difference observed was in the infested control, which exhibited lower mean shoot weights than the uninfested control (Fig. 2). Fresh shoot weight of the treatments did not differ significantly from

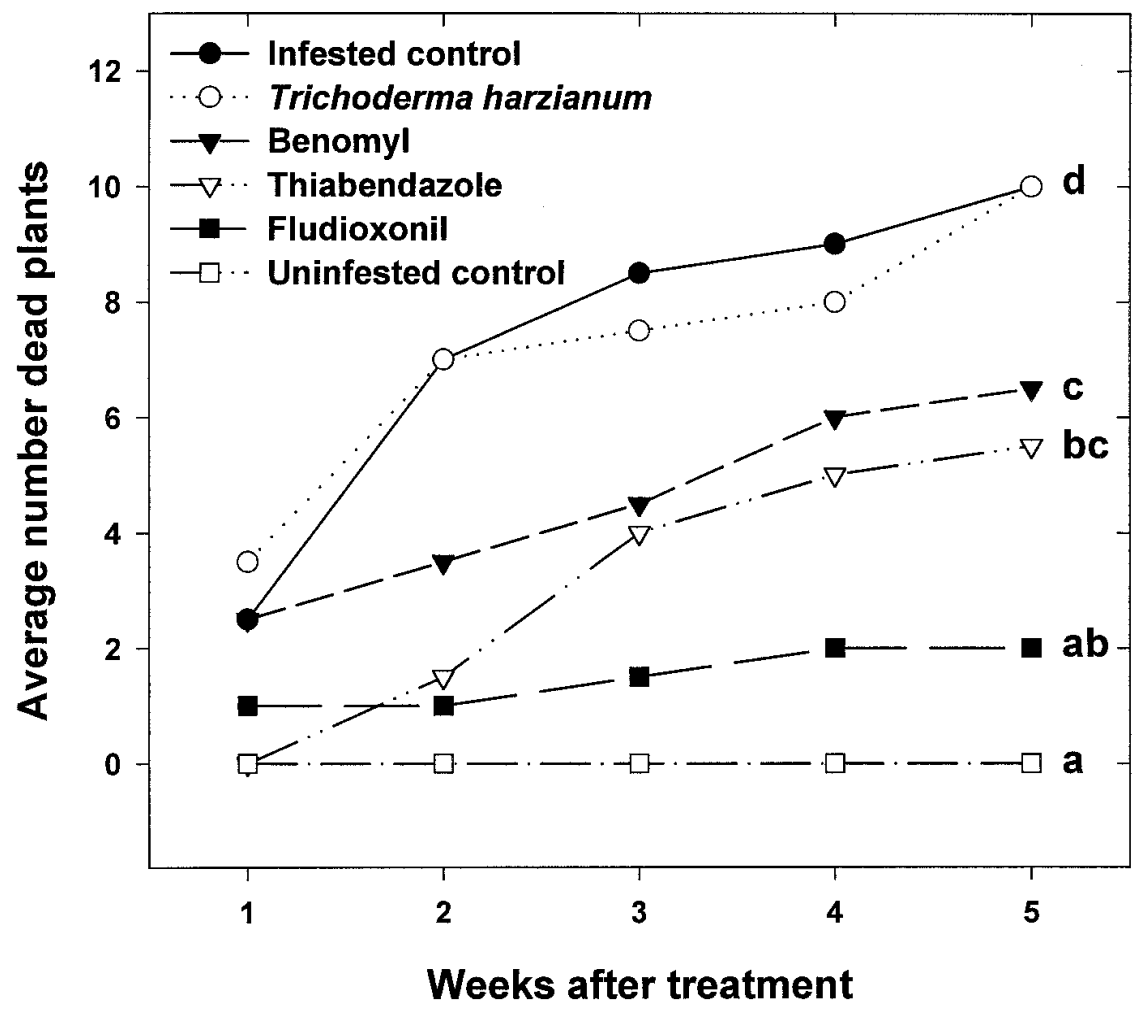

Fig. 1. Average number of asparagus plants dead in two greenhouse experiments when grown in soil infested with a high level of Fusarium proliferatum and $F$. oxysporum f. sp. asparagi and treated with a chemical or biological control product. Different letter notation indicates significant differences between treatments after 5 weeks.

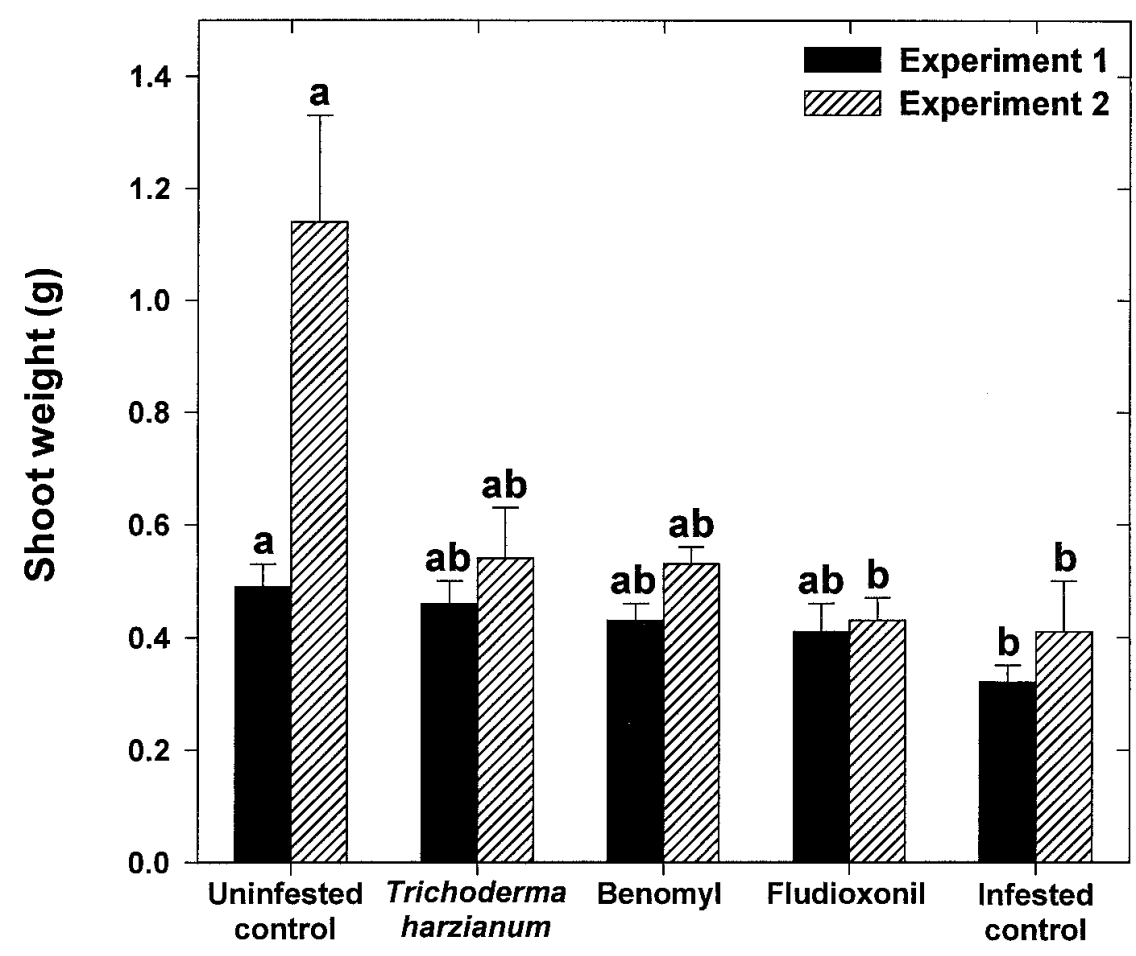

\section{Treatments}

Fig. 2. Shoot weight of asparagus seedlings from two greenhouse experiments when grown in soil infested with a low level of Fusarium proliferatum and $F$. oxysporum f. sp. asparagi and treated with a chemical or biological control product. Error bars represent standard error, and different letter notation indicates significant difference. 


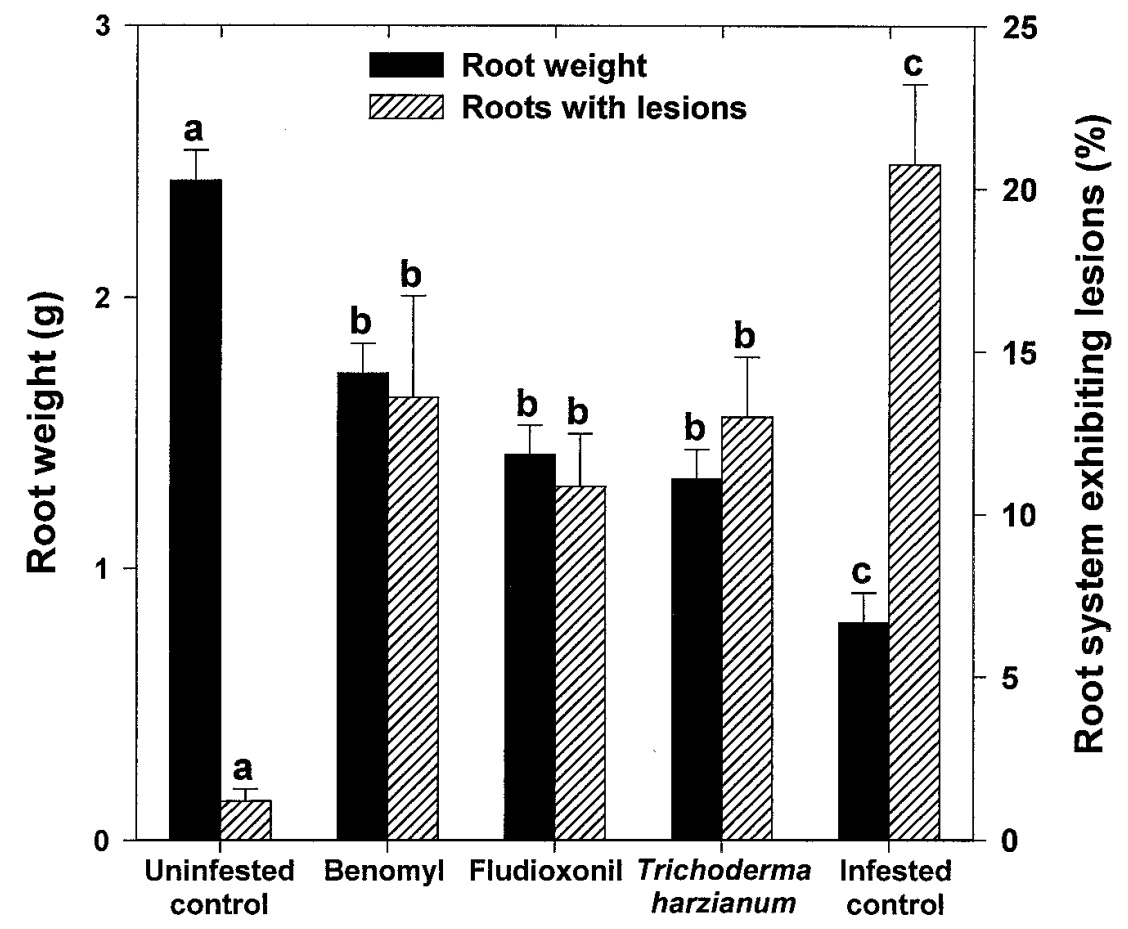

Treatments

Fig. 3. Root weight of asparagus seedlings and roots of asparagus seedlings exhibiting lesions (percent) from two greenhouse experiments when grown in soil infested with a low level of Fusarium proliferatum and $F$. oxysporum f. sp. asparagi and treated with a chemical or biological control product. Error bars represent standard error, and different letter notation indicates significant difference.

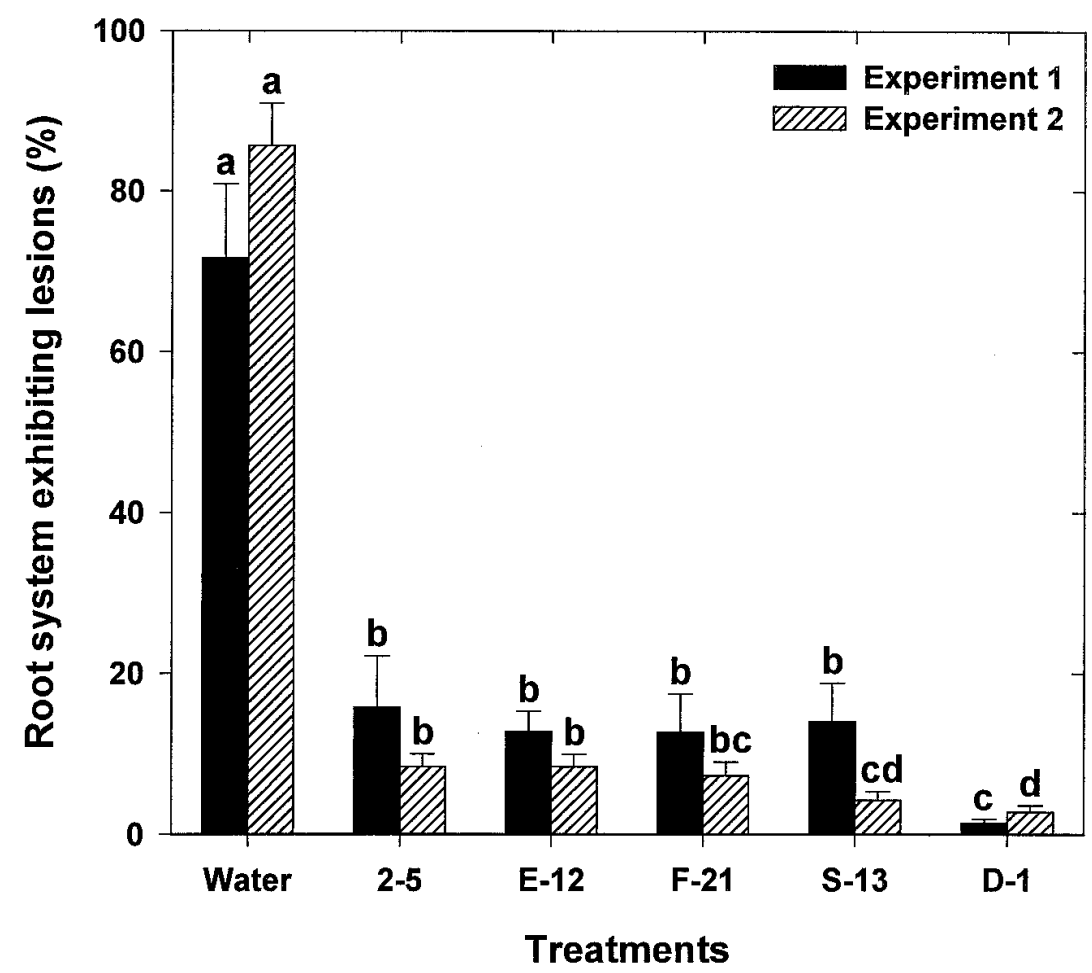

Fig. 4. Root system of asparagus seedlings exhibiting lesions (percent) from two growth chamber experiments when grown in culture tubes infested with Fusarium oxysporum f. sp. asparagi and treated with nonpathogenic F. oxysporum. Error bars represent standard error, and different letter notation indicates significant difference. either control. In the second low inoculum experiment, the shoot weight of the uninfested control was significantly greater than that of the fludioxonil treatment and the infested control. Significant differences among other treatments were not noted. Because the analysis of root weight and root system exhibiting lesions (percent) showed no significant experiment-treatment interaction, the data for each of these parameters were combined. Root weight was significantly greater for the uninfested control than for any other treatment or the infested control (Fig. 3). Root weights for all treatments were significantly greater than the infested control, but were not significantly different from each other. The uninfested control plants had a lower percentage of root system with lesions than any other treatment (Fig. 3). All treatments resulted in reduction of root lesions compared with the infested control, but did not differ significantly from one another, and were greater than in the uninfested control.

In both greenhouse studies evaluating the effectiveness of nonpathogenic $F$. $o x$ ysporum isolates, both treatments, $F$. oxysporum f. sp. asparagi and $F$. proliferatum with nonpathogenic $F$. oxysporum and $F$. oxysporum f. sp. asparagi and $F$. proliferatum alone, resulted in significantly more plant death than the uninfested control. No significant differences in plant death were found between asparagus plants growing in media infested with $F$. oxysporum f. sp. asparagi and $F$. proliferatum alone, and those infested with pathogenic Fusarium spp. and nonpathogenic isolates.

Growth chamber studies with nonpathogenic forms of $\boldsymbol{F}$. oxysporum. All five of the selected nonpathogenic $F$. $o x$ ysporum isolates significantly reduced root disease compared with the infested control in two growth chamber experiments with F. oxysporum f. sp. asparagi (Fig. 4). Isolate D-1 was significantly more effective at reducing root lesions than all other isolates in experiment 1 , and significantly more effective than all isolates except for $\mathrm{S}-13$ in experiment 2. Isolate $\mathrm{S}-13$ was significantly more effective than isolates $2-5$ and E-12 in experiment 2 only.

No significant treatment-experiment interaction occurred in trials with the pathogen $F$. proliferatum; thus, the data from these experiments were combined (Fig. 5). All isolates showed significant disease reduction compared with the infested control, although isolate D-1 was significantly less effective than the other isolates.

Field trials using fungicides and biological controls. Although the trials were conducted in seedling fields considered to be highly infested with pathogenic Fusarium spp., mean root lesions did not exceed $3 \%$ in the untreated control or the treatment plots in either field. Root infection (percent) was not significantly different among treatments, and no consistent 
trends among the measured parameters were observed between the two replicate fields (data not shown).

\section{DISCUSSION}

Fusarium spp. pathogenic to asparagus are found in all Michigan soils, and Fusarium decline has become a serious production limitation as pathogen populations have built up in fields previously planted with the crop $(11,18)$. Previous studies have evaluated the potential of nonpathogenic $F$. oxysporum to control disease caused by $F$. oxysporum f. sp. asparagi $(3,7)$, but the effect of nonpathogenic isolates on $F$. proliferatum has not been studied previously. Several new products (chemical and biological) for the control of root disease also have been developed in the last several years that have not been tested for their ability to control Fusarium crown and root rot of asparagus. However, our goal to develop an effective management strategy utilizing a commercially available biological control product ( $T$. harzianum strain T-22), nonpathogenic isolates of $F$. oxysporum, and fungicides has met with limited success.

Greenhouse studies with asparagus seedlings in soil using fungicides and a biological control product indicated that $T$. harzianum strain T-22, benomyl, and fludioxonil increased root weight and decreased root disease compared with the infested control when a low level of $F$. proliferatum and $F$. oxysporum f. sp. asparagi was used. The fungicide fludioxonil limited disease caused by Fusarium spp. at both low and high inoculum levels. This result shows the potential of this fungicide for use in commercial asparagus production, and emphasizes the need for further testing in the field. T. harzianum strain T-22 was not effective when a high rate of inoculum was used, indicating that the effectiveness of this product may be dependent on disease pressure. Benomyl is not currently labeled for use on asparagus in Michigan, and experiments by Lacy (21) indicated that it was not effective in reducing disease when applied as a dip to 1-year-old crowns from seedling nurseries.

When nonpathogenic isolates which effectively limited both $F$. proliferatum and F. oxysporum f. sp. asparagi in culture tube tests were mixed and tested in greenhouse studies with asparagus seedlings grown in soil, they were not effective in controlling disease. It is likely that the high level of pathogen inoculum $(180,000 \mathrm{CFU} / \mathrm{g}$ of soil) used in this experiment overwhelmed and out-competed the nonpathogens. Hartung et al. (18) found that levels of Fusarium spp. in asparagus field soils in Michigan were generally much lower than this (between 0 and 60,000 CFU of Fusarium spp. per gram of sieved soil). Furthermore, the numbers of Hartung et al. (18) represent both pathogenic and nonpathogenic Fusarium spp. found in soil, although $F$. proliferatum isolates were likely underestimated because they are found more consistently on plant residue than in soil. It is also possible that, because the nonpathogenic isolates did not have a week to colonize the asparagus seedlings (as they did in the growth chamber tubes), they could not provide adequate protection. The added complexity of the soil system or the method of inoculation could have accounted for the failure of these isolates to control disease in the greenhouse system. Still, the potential for disease control with these nonpathogenic isolates has been demonstrated, and further field tests would be valuable.

Our attempt to test fungicides and biological control products under commercial field conditions was not successful. The low level of seedling infection in the fields where the treatments were tested may be attributed to environmental conditions, and may have been responsible for the absence of significant or consistent differences between the treatments. Previous research has suggested that dry conditions favor disease development in seedlings (16, W. Elmer, personal communication). In addition, Michigan growers have observed that the critical time for seedling infection by Fusarium spp. is during establishment (J. Bakker, Director, Oceana County Asparagus Research Farm, personal communication). Rainfall during the early part of the season was $13.35 \mathrm{~cm}$ (27 April through 12 June), and total rainfall was $41.28 \mathrm{~cm}$ (27
April through 6 October), which did not result in drought conditions.

Biocontrol activity of nonpathogenic isolates of $F$. oxysporum has been recognized by others $(3,7,31)$. However, only Damicone et. al. (7) were successful in demonstrating disease control in the field using uninfested, greenhouse grown seedlings dipped in $0.4 \%$ methyl cellulose containing nonpathogenic $F$. oxysporum spores (4 to $6 \times 10^{6}$ spores $/ \mathrm{ml}$ ). Both Blok et. al. and Tu et. al. $(3,31)$ failed to suppress disease in fields amended with soil containing nonpathogenic Fusarium spp., and an effective disease control product has not been developed for the field. Studies by other researchers $(9,21)$ have suggested that Fusarium infection in seedling nurseries may be the most important factor in predisposing asparagus plantings to decline, and have not demonstrated disease control with fungicides when crowns were already infected; therefore, this may be the best place to initiate root colonization by nonpathogenic species.

Future investigations on the use of nonpathogenic $F$. oxysporum may want to consider the optimal stage of plant development for nonpathogen colonization, different methods for infesting plants with nonpathogenic isolates, and the level of inoculum needed to obtain effective disease control. Using a mixture of avirulent strains may provide enhanced disease suppression against a range of pathogenic Fusarium isolates, and using native iso-

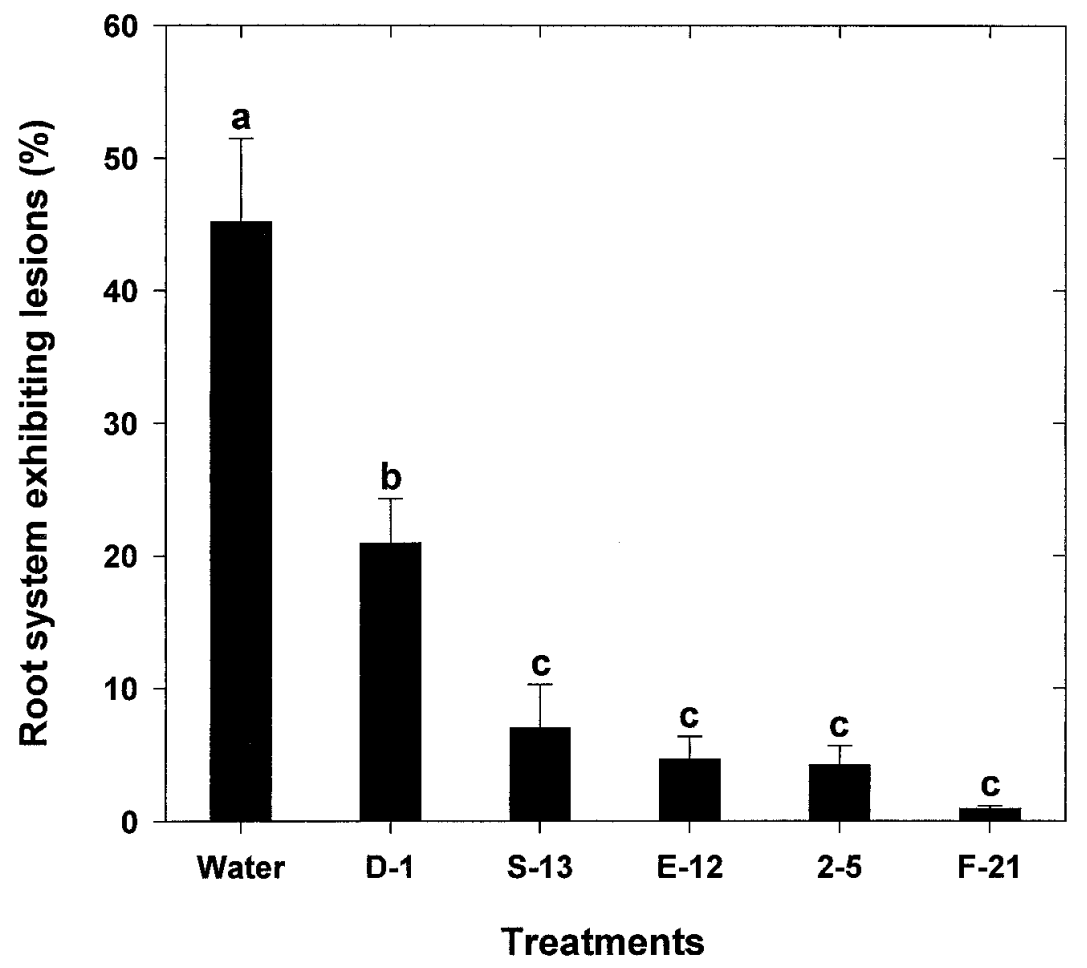

Fig. 5. Root system of asparagus seedlings exhibiting lesions (percent) from two growth chamber experiments when grown in culture tubes infested with Fusarium proliferatum and treated with nonpathogenic F. oxysporum. Error bars represent standard error, and different letter notation indicates significant difference. 
lates may insure that inoculum is able to survive and proliferate in the conditions under which it may be used. New chemical and biological control products should be tested further for their effectiveness against Fusarium spp. pathogenic to asparagus, and integrated strategies for disease control such as those developed for other Fusarium pathogens $(2,5,27)$ could be explored.

\section{ACKNOWLEDGMENTS}

We thank B. Cortright and W. Quackenbush for assistance in setup and maintenance of field plots.

\section{LITERATURE CITED}

1. Arriola, L. L. 1997. Arbuscular mycorrhizal fungi and Trichoderma harzianum in relation to border cell production and Fusarium root rot of asparagus. M.S. thesis, Michigan State University, E. Lansing.

2. Beale, R. E., and Pitt, D. 1990. Biological and integrated control of Fusarium basal rot of Narcissus using Minimedusa polyspora and other micro-organisms. Plant Pathol. 39:477488 .

3. Blok, W. J., Zwankhuizen, M. J., and Bollen G. J. 1997. Biological control of Fusarium oxysporum f. sp. asparagi by applying nonpathogenic isolates of $F$. oxysporum. Biocontrol Sci. Technol. 7:527-541.

4. Cassini, R. C., El Medawar, S., and Cassini, R. P. 1985. A biological control technique to prevent Fusarium decline in the fields. Pages 228-234 in: Proc. Sixth Int. Asparagus Symp. E. C. Lougheed and H. Tiessen, eds. Guelph, Ontario, Canada.

5. Chakravarty, P., Peterson R. L., and Ellis B. E. 1990. Integrated control of Fusarium damping-off in red pine seedlings with the ectomycorrhizal fungus Paxillus involutus and fungicides. Can. J. For. Res. 20:12831288.

6. Damicone, J. P., Cooley, D. R., and Manning, W. J. 1981. Benomyl in acetone eradicates Fusarium moniliforme and Fusarium oxysporum from asparagus seed. Plant Dis. 65:892-893.

7. Damicone, J. P., and Manning, W. J. 1982. Avirulent strains of Fusarium oxysporum protect asparagus seedlings from crown rot. Canadian Journal of Plant Pathol. 4:143-146.

8. Davis, D. 1967. Cross-protection in Fusarium wilt diseases. Phytopathology 57:311-314.

9. Di Lenna, P., and Foletto, B. 1990. Effect of nursery management on subsequent Fusarium decline of asparagus in field. Acta Hortic. 271:299-303.

10. Elmer, W. H. 1989. Effects of chloride and nitrogen form on growth of asparagus infected by Fusarium spp. Plant Dis. 73:736740 .

11. Elmer, W. H., Johnson, D. A., and Mink, G. I. 1996. Epidemiology and management of the diseases causal to asparagus decline. Plant Dis. 80:117-125.

12. Elmer, W. H., LaMondia, J. A., and Taylor, G. S. 1997. Asparagus cultivar trials in Connecticut. Pages 420-426 in: The IX Int. Asparagus Symp. B. Benson, ed. Pasco, WA.

13. Elmer, W. H., and Stephens, C. T. 1989. Classification of Fusarium oxysporum f. sp. asparagi into vegetatively compatible groups. Phytopathology 79:88-93.

14. Faloon, P. J., and Fauser-Kevern, H. A. 1996. Effect of thiabendazole (Tecto 20S) and metalaxyl (Ridomil MZ72) on asparagus establishment in replant soil. Acta Hortic. 415:289-295.

15. Fantino, M. G. 1990. Research on asparagus decline in Italy. Acta Hortic. 271:291-298.

16. Graham, K. M. 1955. Seedling blight, a Fusarial disease of asparagus. Can. J. Bot. 33:374-404.

17. Grogan, R. G., and Kimble, K. A. 1959. The association of Fusarium wilt with the asparagus decline and replant problem in California. Phytopathology 49:122-125.

18. Hartung, A. C., Stephens, C. T., and Elmer, W. H. 1990. Survey of Fusarium populations in Michigan's asparagus fields. Acta Hortic. 271:395-401

19. Hervas, A., Trapero-Casas, J. L., and JimenezDiaz, R. M. 1995. Induced resistance against Fusarium wilt of chickpea by nonpathogenic races of Fusarium oxysporum f. sp. ciceris and nonpathogenic isolates of $F$. oxysporum. Plant Dis. 79:1110-1116.

20. Komada, H., 1975. Development of a selective medium for quantitative isolation of Fusarium oxysporum from natural soil. Rev. Plant Prot. Res. 8:114-124.

21. Lacy, M. L. 1979. Effects of chemicals on stand establishment and yields of asparagus. Plant Dis. Rep. 63:612-616.

22. Larkin, R. P., Hopkins D. L., and Martin F. N. 1996. Suppression of Fusarium wilt of water- melon by nonpathogenic Fusarium oxysporum and other microorganisms recovered from disease-suppressive soil. Phytopathology 86:812-819.

23. Mandeel, Q., and Baker, R. 1991. Mechanisms involved in biological control of Fusarium wilt of cucumber with strains of nonpathogenic Fusarium oxysporum Phytopathology 81:462-469.

24. Marois, J. J. 1993. Biological control of diseases caused by Fusarium oxysporum. Pages 77-81 in: Fusarium Wilt of Banana. R. C. Ploetz, ed., American Phytopathological Society Press, St. Paul, MN.

25. Nelson, P. E., Toussoun, T. A., and Marsas, W. F. O. 1983. Fusarium Species: An Illustrated Manual For Identification. The Pennsylvania State University Press, University Park.

26. Oyarzun, P. J., Postma, J., Luttikholt, A. J. G., and Hoogland, A. E. 1994. Biological control of foot and root rot in pea caused by Fusarium solani with nonpathogenic Fusarium oxysporum isolates. Can. J. Bot. 72:843-852.

27. Sivan, A., and Chet, I. 1993. Integrated control of Fusarium crown and root rot of tomato with Trichoderma harzianum in combination with methyl bromide or soil solarization. Crop Prot. 12:380-386.

28. Sokal, R. R., and Rohlf, J. F. 1969. Biometry: The Principles and Practice of Statistics in Biological Research. W. H. Freeman and Company, San Francisco.

29. Stephens, C. T., De Vries, R. M., and Sink, K C. 1989. Evaluation of Asparagus species for resistance to Fusarium oxysporum f. sp. asparagi and $F$. moniliforme. HortScience 24:365-368.

30. Stephens, C. T., and Elmer, W. H. 1988. An in vitro assay to evaluate sources of resistance in Asparagus spp. to Fusarium crown and root rot. Plant Dis. 72:334-337.

31. Tu, C. C., Cheng, Y. H., and Cheng, A. S. 1990. Recent advance in biological control of Fusarium wilt of asparagus in Taiwan. Acta Hortic. 271:353-357.

32. Wacker, T. L. 1988. The role of vesiculararbuscular mycorrhizal fungi in the asparagus (Asparagus officinalis L.) agroecosystem. M. S. thesis, Michigan State University, E. Lansing.

33. Windels, C. E., Burnes, P. M., and Kommedahl, T. 1988. Five-year preservation of Fusarium species on silica gel and soil. Phytopathology 78:107-109. 